\title{
Cholangioscopy and electrohydraulic lithotripsy in the management of fistulated pancreatic duct stones
}

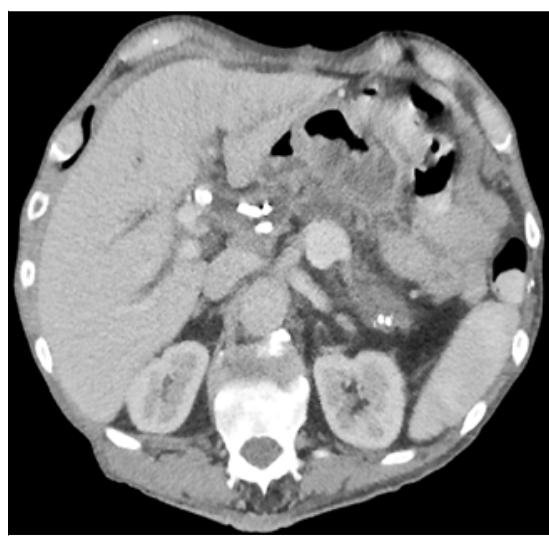

Fig. 1 Computed tomography image showing the features of chronic pancreatitis with a densely calcified stone.

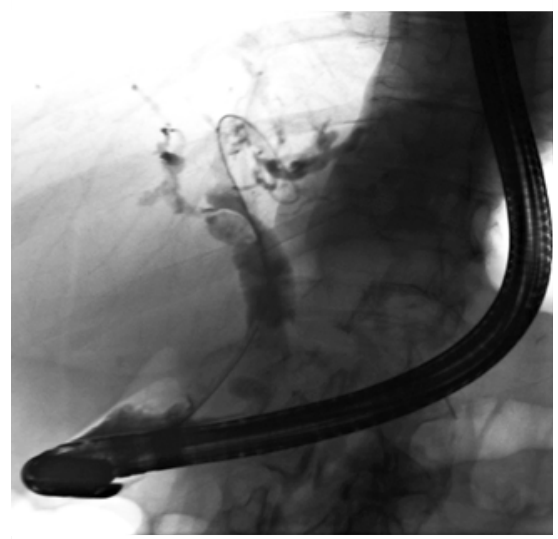

- Fig. 2 Endoscopic retrograde cholangiopancreatography showing heavily calcified stones within the extrahepatic ducts.

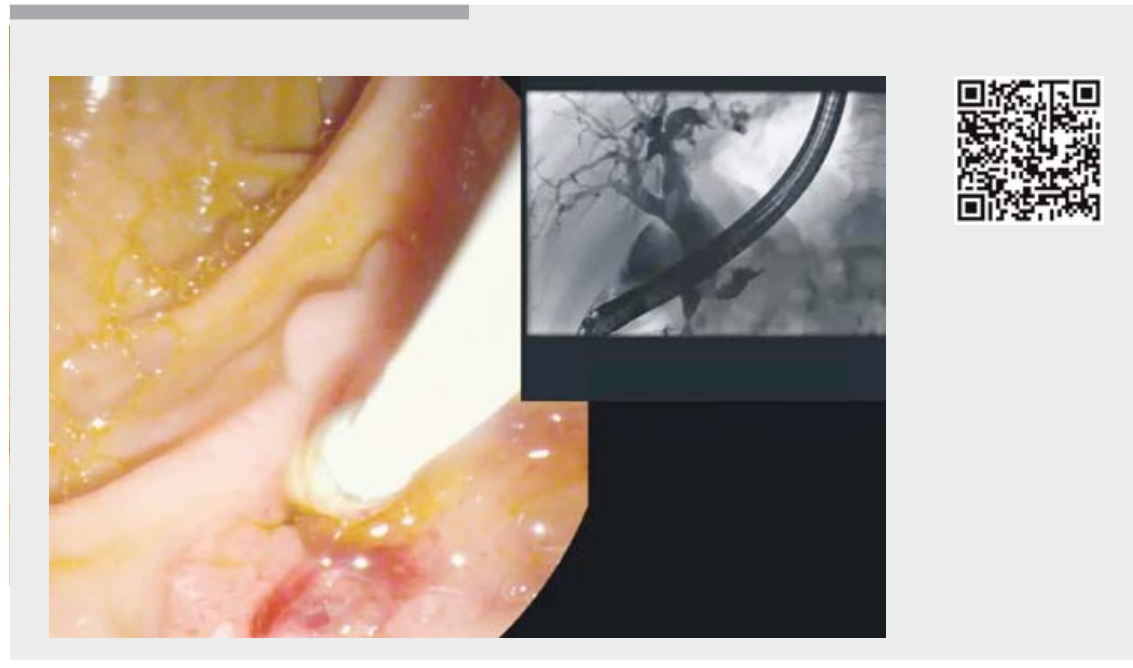

Video 1 Cholangioscopy and electrohydraulic lithotripsy are performed to treat fistulated pancreatic duct stones.

An 80-year-old man with a history of alcohol-induced chronic calcific pancreatitis presented with new pain and obstructive jaundice. The computed tomography (CT) scan confirmed features of chronic pancreatitis and showed a heavily calcified stone within the bile duct and associated dilatation ( $\triangleright$ Fig.1). Endoscopic retrograde cholangiopancreatography (ERCP) demonstrated dense calcified stones within the extrahepatic bile ducts (> Fig. 2).

Stone extraction was unsuccessful with the extraction balloon and mechanical lithotriptor. A plastic pigtail biliary stent was deployed to assist biliary drainage.

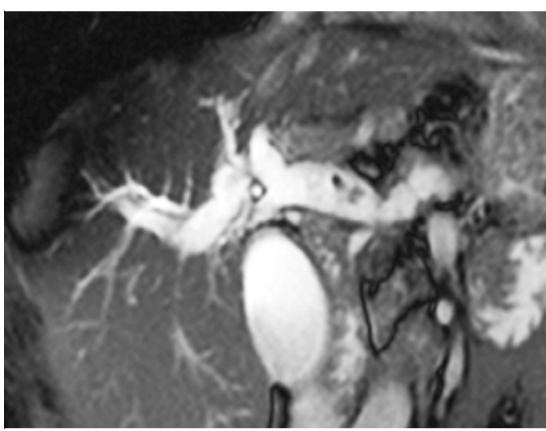

- Fig. 3 Magnetic resonance cholangiopancreatography confirming the presence of a pancreatobiliary fistula.

Subsequent magnetic resonance cholangiopancreatography (MRCP) showed continuity of the pancreatic duct and bile duct, suggesting the presence of a pancreatobiliary fistula ( $\triangleright$ Fig. 3 ).

The patient underwent a further ERCP with peroral transpapillary cholangioscopy ( $\vee$ Video 1$)$. Direct visualization demonstrated a pancreatobiliary fistula associated with the lower bile duct, as well as the presence of white, heavily calcified stones within the extrahepatic bile ducts. Cholangioscopic assessment of the pancreatic duct through the fistula revealed intraluminal papillary projections, consistent with an intraductal papillary mucinous neoplasm (IPMN). Intraductal electrohydraulic lithotripsy (EHL) and subsequent balloon trawl were used to clear the biliary stones. Biopsies confirmed the presence of an IPMN.

Pancreatobiliary fistulas associated with pancreatic IPMN have previously been described; however, we believe this is the first video-reported case of fistulated pancreatolithiasis that was treated with EHL.

Endoscopy_UCTN_Code_CCL_1AZ_2AM 
None

The authors

George Goodchild, Sanjay Sivalokanathan, George Webster

Division of Gastroenterology, Department of Medicine, University College London Hospitals, London, United Kingdom
Corresponding author

George Webster, MD, FRCP

Gastrointestinal Services, University College Hospital, Ground floor West, 250 Euston

Road, London, NW1 2PG, UK

Fax: +44-20-34479218

george.webster@uclh.nhs.uk

\section{Bibliography}

DOI https://doi.org/10.1055/a-0599-0280

Published online: 9.5.2018

Endoscopy 2018; 50: E163-E164

(c) Georg Thieme Verlag KG

Stuttgart · New York

ISSN 0013-726X

\section{ENDOSCOPY E-VIDEOS}

https://eref.thieme.de/e-videos

回回 Endoscopy E-Videos is a free access online section, reporting 回梠: on interesting cases and new techniques in gastroenterological endoscopy. All papers include a high quality video and all contributions are freely accessible online.

This section has its own submission website at

https://mc.manuscriptcentral.com/e-videos 